\title{
Spironolactone for poorly controlled hypertension in type 2 diabetes: conflicting effects on blood pressure, endothelial function, glycaemic control and hormonal profiles
}

\author{
K. Swaminathan • J. Davies • J. George • \\ N. S. Rajendra • A. D. Morris • A. D. Struthers
}

Received: 24 November 2007 / Accepted: 2 February 2008 /Published online: 18 March 2008

(C) Springer-Verlag 2008

\begin{abstract}
Aims/hypothesis Aldosterone antagonism improves endothelial function (and reduces deaths) in chronic heart failure. It is not known whether similar effects occur in other high-risk groups such as patients with diabetes and hypertension. We therefore assessed the full effects of aldosterone blockade in poorly controlled hypertensive patients with type 2 diabetes, focussing on blood pressure, endothelial function, glycaemic control and key hormones.

Methods We performed a randomised, placebo-controlled, double-blind, crossover study on 50 patients with type 2 diabetes and treated but poorly controlled hypertension, comparing spironolactone versus placebo. Patients had their endothelial function assessed by standard forearm venous occlusion plethysmography.

Results There was no significant improvement in endotheliumdependent vasodilatation in response to acetylcholine, despite highly significant reductions in systolic and diastolic blood pressure. However, spironolactone significantly worsened glycaemic control, plasma angiotensin II and cortisol.

Conclusions/interpretation Spironolactone is highly effective in lowering blood pressure in patients with type 2 diabetes and poorly controlled hypertension on standard treatment, but does not improve vascular endothelial function in this group. We speculate that any tendency for the spironolactoneinduced lowering of blood pressure to improve endothelial function is offset by its tendency to worsen glycaemic control
\end{abstract}

K. Swaminathan $(\bowtie) \cdot J$. Davies $\cdot$ J. George $\cdot$ N. S. Rajendra $\cdot$

A. D. Morris $\cdot$ A. D. Struthers

Division of Medicine and Therapeutics,

Ninewells Hospital and Medical School,

Dundee DD1 9SY, UK

e-mail: krishnan.swaminathan@nhs.net and increase the levels of angiotensin II and even possibly cortisol.

Trials Registry no.: ISRCTN 76558770

Keywords Aldosterone · Blockade · Cardiovascular . Endothelium · Glycaemic control · Hormones ·

Hypertension · Type 2 diabetes

$\begin{array}{ll}\text { Abbreviations } \\ \text { ARB } & \text { angiotensin receptor blocker } \\ \text { BNP } & \text { brain natriuretic peptide } \\ \text { FBF } & \text { forearm blood flow } \\ \text { PIIINP } & \text { procollagen III N-terminal peptide } \\ \text { RAAS } & \text { renin-angiotensin-aldosterone system }\end{array}$

\section{Introduction}

Patients with diabetes are at particularly high risk of cardiovascular disease $[1,2]$. The combination of diabetes and hypertension is a particularly strong cardiovascular risk factor and blood pressure control is often suboptimal in patients with diabetes [3, 4]. Blocking the renin-angiotensinaldosterone system (RAAS) has obviously been a very successful therapeutic strategy in both heart failure and diabetes mellitus. In heart failure, the concept of blocking the RAAS has been taken a stage further, with aldosterone blockade, in addition to ACE inhibitors, now shown to reduce mortality rates $[5,6]$. Thus it is now legitimate to ask whether such benefits would also occur if aldosterone blockade were given on top of ACE inhibition in patients with diabetes mellitus. This is a distinct possibility, as both heart failure and diabetes are strongly characterised by high 
levels of oxidative stress while mineralocorticoid blockade is thought to produce many of its benefits by reducing oxidative stress. Also of interest is a recent proof-of-concept, pilot study [7] showing that short-term treatment with an aldosterone antagonist was better than hydrochlorthiazide in improving coronary circulatory function in diabetic patients on ACE inhibitors, again suggesting a major role for mineralocorticoid receptor in diabetes. It seems a sensible first approach to see whether aldosterone blockade favourably effects the same factors in diabetes that are thought to contribute to the favourable effects on mortality rates in heart failure. The key factors favourably affected by aldosterone blockade in heart failure are endothelial function and myocardial collagen markers (procollagen III N-terminal peptide [PIIINP]) $[8,9]$. These factors could potentially be altered by aldosterone blockade in diabetes mellitus as well.

As a backdrop to this question, we previously found that, to our surprise, spironolactone actually worsened the key prognostic marker of endothelial function in a normotensive population of patients with type 2 diabetes, while also worsening glycaemic control [10]. The situation could, however, be very different in patients with diabetes and poorly controlled hypertension. This possibility arises because even in the Eplerenone Post-Acute Myocardial Infarction Heart Failure Efficacy and Survival Study (EPHESUS) trial [6], aldosterone blockade significantly improved mortality rates only in the subgroup of heart failure patients who were also hypertensive and/or had a high pulse pressure at baseline. The second major reason for studying this group is because poor blood pressure control is common in diabetes and aldosterone blockade is often recommended in 'resistant' hypertension because it is an effective antihypertensive in those with frankly high blood pressures [11, 12]. Yet the full effects of spironolactone in patients with diabetes and poorly controlled hypertension have not been studied before.

\section{Methods}

\section{Study procedures}

This study was carried out in the Division of Medicine and Therapeutics at Ninewells Hospital, Dundee, UK. Patients were recruited from the Diabetes Clinic at Ninewells Hospital and through GP practices in Dundee. All participants gave written informed consent to participate in the study, which had prior approval by the Tayside Committee on Medical Research Ethics and was conducted in accordance with the Declaration of Helsinki.

We recruited 50 patients with type 2 diabetes mellitus and poorly controlled hypertension who were on standard treatment. All patients were on either ACE inhibitors or angiotensin receptor blockers (ARB). The doses used were close to those recommended, e.g. mean of $21.5 \mathrm{mg}$ for lisinopril and $8.5 \mathrm{mg}$ for ramipril, which were the commonest ACE inhibitors used. Patients underwent screening by history, clinical examination, blood investigations and a baseline ECG. In all instances, blood pressure was recorded using the Omron HEM-705CP system (Omron Health Care Company, Kyoto, Japan) and an average of two readings was used with the patient sitting and rested. Poorly controlled hypertension was defined as a systolic blood pressure of $>140 \mathrm{mmHg}$ and/or a diastolic blood pressure of $>80 \mathrm{mmHg}$ in patients on standard treatment for hypertension. Patients were excluded if they had: (1) a blood pressure $<140 \mathrm{mmHg}$ systolic and $<80 \mathrm{mmHg}$ diastolic (done to make the study population not too heterogeneous and to select a more hypertensive group of patients, although the target systolic blood pressure in type 2 diabetes was $130 \mathrm{mmHg}$ ); (2) been admitted to hospital within the last 4 weeks; (3) a history of alcohol abuse, liver or renal impairment, or heart failure, or if they were on potassium-sparing diuretics or warfarin (procedural risks). We also excluded patients on insulin due to procedural issues as the endothelial function test was done in a fasting state.

After baseline assessments, study patients were randomised in a double-blind crossover fashion to spironolactone (4 weeks) or placebo (4 weeks). The starting dose of spironolactone was $25 \mathrm{mg}$ once daily. If the potassium levels were $<5 \mathrm{mmol} / \mathrm{l}$ after the first week, the dose was increased to two tablets of spironolactone $(50 \mathrm{mg})$ or to two tablets of matching placebo. After a 4 week treatment period, each patient attended a $3 \mathrm{~h}$ morning study after an overnight fast, for assessment of endothelial function. This was to avoid the recognised diurnal fluctuations in endothelial function [13] Also, they were requested to refrain from caffeine, alcohol or smoking for $12 \mathrm{~h}$ prior to the test. Following the procedure, there was a 2 week washout period, after which the same participants were crossed over to 4 weeks of the opposite treatment followed by a repeat endothelial function test at the same time of the day. Endothelial function is known to be changed quickly by treatments that alter it [14], so a 4 week treatment period followed by a 2 week washout period was sufficient to observe changes in endothelial function.

Endothelial function testing was performed with the patient supine, in a temperature controlled room at $20-24^{\circ} \mathrm{C}$. Blood pressure was measured by an Omron HEM-705CP monitor prior to the start of the test as previously mentioned. Blood samples were taken for renal function, liver function, $\mathrm{HbA}_{1 \mathrm{c}}$, glucose, magnesium, insulin, brain natriuretic peptide (BNP) (Bachem, St Helens, UK), procollagen type III Nterminal peptide (Oxford Biosystems, Oxford, UK). Patients then underwent cannulation of the non-dominant brachial artery with a 27 gauge steel needle (Coopers Needleworks, Birmingham, UK) mounted on to a 16 gauge epidural 
catheter (Portex, Kent, England) under local anaesthesia. Normal $0.9 \%$ saline was infused (3100 syringe pump; Graseby, Watford, UK) for $10 \mathrm{~min}$ prior to the assessment of baseline readings. Three baseline forearm blood flow (FBF) readings taken 10 min apart were measured by means of forearm venous occlusion plethysmography. This technique has been well described [15-18].

After the baseline resting flows were established, FBF was measured during the last $2 \mathrm{~min}$ of $7 \mathrm{~min}$ drug infusions. Drugs infused were acetylcholine 50 and $100 \mathrm{nmol} / \mathrm{min}$ (Novartis, Basel, Switzerland), sodium nitroprusside 12.6 and $37.8 \mathrm{nmol} / \mathrm{min}$ (Mayne Pharma, Leamington, UK). Each drug infusion was separated by a washout period with $0.9 \%$ saline to normalise flows. All FBF values are expressed as $\mathrm{ml} \mathrm{min}{ }^{-1} 100 \mathrm{ml}^{-1}$ forearm tissue.

Statistical analysis

Power calculations showed that with 38 participants randomly allocated to spironolactone and placebo in a crossover study, there would be an $80 \%$ power to demonstrate a $20 \%$ treatment difference in endothelial function at two dose levels, this being based on previous data with the technique in our department. Data were analysed using SPSS for Windows 14.0 (SPSS, Chicago, IL, USA). Results of clinical parameters are expressed as mean $\pm \mathrm{SD}$ (unless stated otherwise) and data from forearm venous occlusion plethysmography are expressed as mean \pm SEM. Comparisons between groups used paired $t$ test or Wilcoxon signed rank test for non-normal data. FBFs for individual patients were compared by repeated measures ANOVA and the Bonferroni method of calculating $95 \% \mathrm{CI}$, correcting for multiple comparisons for within group effects, treatment order effects and carryover effects. A probability value of $p<0.05$ was considered significant.

\section{Results}

Participant characteristics

Of the 50 patients recruited, 38 patients completed the study successfully. Of the 12 who failed to complete the study, one developed significant hyperkalaemia $\left(\mathrm{K}^{+}>6 \mathrm{mmol} / \mathrm{l}\right)$ on spironolactone, four had to withdraw from the study due to technical difficulties in cannulation and seven dropped out because they could not tolerate the plethysmography test. Of the 38 patients, six were diet-controlled, 16 were on metformin alone, nine were on a combination of metformin and sulfonylurea, six were on a combination of metformin and a glitazone and one was on a combination of sulfonylurea and a glitazone. Twenty-nine patients were on ACE inhibitors and nine were on ARB. All 38 participants underwent treatment with spironolactone and placebo. The starting dose of spironolactone was $25 \mathrm{mg} /$ day. The dose was increased to $50 \mathrm{mg}$ /day after 1 week in 24 participants, with 14 patients having to stay on the $25 \mathrm{mg} /$ day dose based on the potassium results after a week's treatment (if $\mathrm{K}^{+}>5 \mathrm{mmol} / \mathrm{l}$, the dose was not increased). The average dose of spironolactone for all patients during the course of 4 weeks was $35 \mathrm{mg}$. Spironolactone was well tolerated with no particular adverse effects. The baseline clinical characteristics are summarised in Table 1.

\section{Biochemical parameters}

For an overview of the biochemical parameters, see Table 2.

Urea, electrolytes and $H b A_{l c}$ There was a significant increase in potassium levels with spironolactone by a mean of $0.37 \mathrm{mmol} / 1(p<0.001,95 \%$ CI $0.23-0.45)$ compared with placebo. Sodium level was decreased by a mean of $1.1 \mathrm{mmol} / 1(p=0.01,95 \% \mathrm{CI}-2.02,-0.23)$, and urea and creatinine levels were increased by a mean of $0.7 \mathrm{mmol} / \mathrm{l}$ $(p<0.001,95 \%$ CI $0.33,1.17)$ and $5.9 \mu \mathrm{mol} / 1(p<0.001$, $95 \%$ CI $3.41,8.8)$, respectively. We also saw a significant increase in $\mathrm{HbA}_{1 \mathrm{c}}$ by $0.21 \%$ with spironolactone compared with placebo $(p=0.01,95 \%$ CI $0.05,0.37)$.

PIIINP, BNP, aldosterone, cortisol and angiotensin II PIIINP levels were significantly lower by $0.46 \mu \mathrm{g} / \mathrm{l}$ with spironolactone compared with placebo $(p=0.005,95 \% \mathrm{CI}$ $-0.79,0.13$ ). However, BNP levels were similar between

Table 1 Baseline patient characteristics

\begin{tabular}{lc}
\hline Characteristic & Value \\
\hline Age, years (range) & $62.6(48-78)$ \\
BMI (kg/m ${ }^{2}$ ) & $30.6(3.8)$ \\
SBP (mmHg) & $162.7(17.2)$ \\
DBP (mmHg) & $88.9(9.2)$ \\
Sodium (mmol/l) & $140.1(2.6)$ \\
Potassium (mmol/l) & $4.3(0.3)$ \\
Urea (mmol/l) & $6.1(1.8)$ \\
Creatinine ( $\mu$ mol/l) & $94.4(18.3)$ \\
HbA $A_{1 \mathrm{c}}(\%)$ & $7.03(1.5)$ \\
Total cholesterol (mmol/l) & $4.2(0.8)$ \\
Sex (male:female) & $28: 10$ \\
ACE inhibitor/ARB (n/n) & $29 / 9$ \\
Calcium channel blockers $(\%)$ & 55.3 \\
Thiazides $(\%)$ & 18.4 \\
Beta blockers $(\%)$ & 26.3 \\
Doxazosin (\%) & 18.4 \\
Statins (\%) & 71.1 \\
Smokers, \% (non smokers) & $23.7(76.3)$ \\
\hline
\end{tabular}

Unless otherwise indicated, values are mean (SD), participants $n=38$ DBP, diastolic blood pressure; SBP, systolic blood pressure 
Table 2 Mean haemodynamic and biochemical parameters during each treatment phase

\begin{tabular}{|c|c|c|c|c|}
\hline Parameter & Participants $(n)$ & Spironolactone & Placebo & $p$ value \\
\hline SBP (mmHg) & 38 & $135.5(16.4)$ & $149.7(16.7)$ & $<0.001$ \\
\hline DBP (mmHg) & 38 & $75.5(9.5)$ & $80.6(10.8)$ & 0.001 \\
\hline Sodium (mmol/1) & 38 & $139.3(2.6)$ & $140.4(2.5)$ & 0.01 \\
\hline Potassium (mmol/1) & 38 & $4.8(0.37)$ & $4.4(0.30)$ & $<0.001$ \\
\hline Urea $(\mathrm{mmol} / \mathrm{l})$ & 38 & $6.9(2.0)$ & $6.2(1.7)$ & $<0.001$ \\
\hline Creatinine $(\mu \mathrm{mol} / 1)$ & 38 & $100.9(23.2)$ & $95.0(20.2)$ & $<0.001$ \\
\hline $\mathrm{HbA}_{1 \mathrm{c}}(\%)$ & 38 & $7.26(0.96)$ & $7.05(0.84)$ & 0.01 \\
\hline Magnesium (nmol/1) & 37 & $0.79(0.11)$ & $0.79(0.08)$ & 0.95 \\
\hline Cortisol (nmol/l) & 37 & $597.27(132.08)$ & $505.02(182.40)$ & 0.003 \\
\hline QTc maximum & 37 & $429.65(23.79)$ & $437.37(24.63)$ & 0.01 \\
\hline Aldosterone (pmol/l) & 33 & $264.33(107.81)$ & $150.84(83.1)$ & $<0.001$ \\
\hline Angiotensin II (pmol/l) & 32 & $27.2(6.5)^{\mathrm{a}}$ & $14.1(3.7)^{\mathrm{a}}$ & 0.008 \\
\hline PIIINP (pmol/l) & 34 & $3.26(1.54)$ & $3.73(1.76)$ & 0.005 \\
\hline $\mathrm{BNP}(\mathrm{pg} / \mathrm{ml})$ & 34 & $59.15(14.2)^{\mathrm{a}}$ & $60.35(13)^{\mathrm{a}}$ & 0.626 \\
\hline
\end{tabular}

Values are mean $(\mathrm{SD})$ or ${ }^{\mathrm{a}}(\mathrm{SEM})$

BNP, Brain natriuretic peptide; DBP, diastolic blood pressure; SBP, systolic blood pressure

the two groups $(p=0.626,95 \% \mathrm{CI}-40.5,-38.2)$. There was a significant increase in aldosterone levels with spironolactone compared with placebo by a mean of $113.4 \mathrm{pmol} / 1(p<0.001,95 \%$ CI 79.1, 147.7). Angiotensin II levels were also increased (mean difference $12.2 \mathrm{pmol} / \mathrm{l}$; $p=0.008,95 \%$ CI $1.13,23.38$ ) with spironolactone compared with placebo. Serum cortisol was significantly higher in the spironolactone group than in the placebo group (mean difference $92.35 \mathrm{nmol} / 1 ; p=0.003,95 \%$ CI 37.80 , 146.89; Table 2).

Blood pressure, basal flows and washouts

There was a significant reduction in both systolic and diastolic blood pressures with spironolactone compared with placebo. The mean reductions in systolic and diastolic blood pressures were $14.2 \mathrm{mmHg}(p<0.001,95 \% \mathrm{CI}-19.7$, $-8.6)$ and $5.3 \mathrm{mmHg}(p=0.001,95 \% \mathrm{CI}-8.8,-2.3)$, respectively. Baseline FBF levels while on spironolactone or placebo were not significantly different $(2.37 \pm 0.20$ vs $2.29 \pm 0.13 \mathrm{ml} \mathrm{min}^{-1} 100 \mathrm{ml}^{-1}, p=0.69$ ). For each treatment phase, no significant difference was seen between baseline and washout FBF levels.

Vascular response to acetylcholine and sodium nitroprusside

No significant difference in endothelial function was seen between spironolactone or placebo treatment, whether analysed in the infusion arm alone or as the ratio between the infusion and control arms. The mean percentage increase in FBF in response to acetylcholine (both doses combined) for spironolactone was $90.6 \pm 12.2 \%$ (95\% CI 65.71, 115.52) vs $92.4 \pm 9.5 \%$ (95\% CI $73.14,111.82)$ for placebo, $p=0.8$ (Fig. 1). There was no significant difference in response to sodium nitroprusside between spironolactone and placebo (Fig. 2).

Baseline aldosterone level as a determinant of response to spironolactone

When patients above and below the median baseline level of aldosterone were compared, there were no significant differences between the two groups in the placebo-corrected effect of spironolactone on any parameters including blood pressure, endothelial function, PIIINP and $\mathrm{HbA}_{1 \mathrm{c}}$.

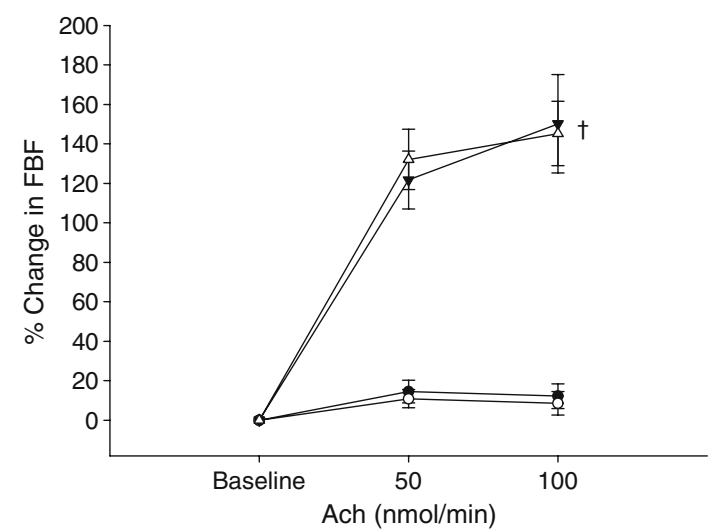

Fig. 1 Percentage increase in FBF response to acetylcholine. ${ }^{\dagger} p=0.8$. Black circles, spironolactone control arm; white circles, placebo control arm; black triangles, spironolactone infusion arm; white triangles, placebo infusion arm. Ach, acetylcholine 


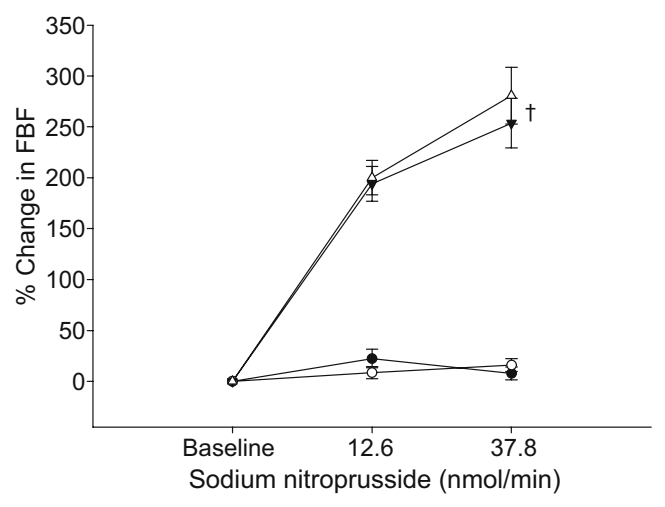

Fig. 2 Percentage increase in FBF response to sodium nitroprusside. ${ }^{\dagger} p=0.4$. Black circles, spironolactone control arm; white circles, placebo control arm; black triangles, spironolactone infusion arm; white triangles, placebo infusion arm. SNP, sodium nitroprusside

\section{Discussion}

Our principal finding was that aldosterone antagonism does not improve endothelial function in type 2 diabetes patients with poorly controlled hypertension, despite considerable reductions in systolic and diastolic blood pressure. On the other hand, spironolactone did not actually worsen endothelial function, as it did in our previous study in normotensive patients with type 2 diabetes [10].

Endothelial dysfunction has been shown to be a good predictor of cardiovascular events [19-24] and has been described as a 'barometer for cardiovascular risk' [25]. We were therefore somewhat surprised by our previous study, which showed that in a normotensive population of patients with type 2 diabetes, spironolactone actually worsened the key prognostic marker of endothelial function [10]. We therefore selected a more hypertensive group of type 2 diabetes patients in the present study, as the additional risk of being hypertensive may well tip the scales in favour of spironolactone improving endothelial function. Furthermore, spironolactone is an effective add-on antihypertensive, but its effects, when used as such in type 2 diabetes patients with hypertension, have not been studied in detail.

In our study, spironolactone in addition to standard antihypertensive therapy resulted in an additional blood pressure reduction of $14.2 \mathrm{mmHg}$ systolic and $5.3 \mathrm{mmHg}$ diastolic compared with placebo. The blood pressure reduction seen in our study is also in line with more dramatic reductions seen with other studies [11, 12], including the largest reported cohort of resistant hypertensive participants, the AngloScandinavian Cardiac Outcomes Trial-Blood Pressure lowering arm [11].

Spironolactone therapy, in our study, resulted in significant decreases in PIIINP levels compared with placebo. PIIINP is a marker of collagen synthesis and myocardial fibrosis. Collagen is a major extracellular matrix protein in the heart and represents an important target for cardioprotective and re-modelling therapy. Excessive collagen deposition leading to cardiac fibrosis is a major determinant of cardiac dysfunction and sudden cardiac death due to increased arrythmogenecity. Circulating or locally produced aldosterone stimulates collagen accumulation in the heart directly via the mineralocorticoid receptors [26] and aldosterone blockade was associated with marked reduction in PIIINP levels in heart failure [9]. In fact, limitation of aldosterone-stimulated collagen synthesis was thought to be a major mechanism explaining the clinical benefit of spironolactone in one trial [5]. We previously saw a similar decrease in PIIINP in a small group $(n=10)$ of hypertensive patients with type 2 diabetes [27], but all other studies of PIIINP reduction with aldosterone blockade have been performed in patients with heart failure [8, 9], where PIIINP levels have been linked to survival outcomes.

Increased QTc intervals are known to be associated with increased mortality rate [28]. Also, a prolonged QTc interval is thought to provide additional prognostic information for cardiovascular morbidity and mortality rates beyond that obtained from conventional risk markers in type 2 diabetic patients with hypertension [29]. Spironolactone therapy, in our study, resulted in a significant reduction in QTc intervals compared with placebo.

Spironolactone therapy also caused a significant rise in serum potassium (mean increase $0.37 \mathrm{mmol} / 1, p<0.001$ ), as would be expected. Only one patient had to withdraw from the study due to severe hyperkalaemia $\left(\mathrm{K}^{+} 6.3 \mathrm{mmol} / \mathrm{l}\right)$. This is reassuring, as there is always a concern of dangerous hyperkalaemia with a combination of ACE inhibitors or ARB and spironolactone, although we acknowledge that the patient numbers are not large enough to draw conclusions on 'safety'. Also, a high-normal potassium level may be beneficial in the context of diabetes and hypertension [30].

However, despite a large reduction in blood pressure, no significant difference in endothelial function was observed with spironolactone compared with placebo (Fig. 1). The question naturally arises as to why spironolactone failed to improve endothelial function in our study patients, despite significant reductions in blood pressure. This finding is interesting as virtually all other antihypertensives improve endothelial function, although the effect of some antihypertensives may be greater than that of others because of possible blood pressure-independent effects on endothelial function [31-35]. We can only speculate that the blood pressure-lowering benefit on endothelial function was prevented as a result of several possible factors, as follows.

First, spironolactone therapy resulted in a small, but statistically significant worsening of glycosylated haemoglobin (\%; mean difference in $\mathrm{HbA}_{1 \mathrm{c}} 0.21, p=0.01$ ) compared with placebo. Intriguingly, a worsening of glycaemic control 
with spironolactone in type 2 diabetes has been previously reported in two other studies $[10,36]$. Furthermore, in the EPHESUS study, aldosterone blockade significantly reduced hypoglycaemia by $43 \%$, which again could be consistent with a worsening of glycaemic control and the attendant negative impact on endothelial function [37-39]. Second, spironolactone doubled plasma levels of angiotensin II, which could be an additional factor in worsening endothelial function [40, 41]. The increase in angiotensin II in patients treated with spironolactone and ACE inhibitors may have been due to non-ACE pathways that mediate the production of angiotensin II $[42,43]$. It could then be speculated that an ARB and spironolactone combination might be better than an ACE inhibitor and spironolactone combination, because the ARB would neutralise the effect of any extra circulating angiotensin II that occurs when spironolactone is added to either ACE inhibitors or an ARB. However, when patients on ARBs were analysed separately in our study, there was again no significant difference in endothelial function between spironolactone and placebo groups, although number of patients ARBs in our study was too small $[n=9]$ to make any firm conclusions in this subgroup. Third, spironolactone significantly increased plasma cortisol, which has been reported before [10]. Several possible mechanisms may mediate the adverse effects of cortisol on endothelial function. Glucocorticoids suppress the production of vasodilators such as nitric oxide and prostacyclins in endothelial cells, reduce production of essential cofactor tetrahydrobiopterin [44], enhance vascular superoxide production and potentiate vascular reactivity by their permissive response to catecholamines on vascular smooth muscle cells [45]. The reason for the increase in cortisol could have been that when the mineralocorticoid receptor is blocked, one clearance route for glucocorticoids is lost, since the mineralocorticoid receptor itself has equal affinity for glucocorticoids and mineralocorticoids.

We, therefore speculate that a combination of worsening glycaemic control, an increase in angiotensin II and an increase in cortisol may have neutralised any beneficial effects of blood pressure-lowering on the endothelium with spironolactone. Admittedly, two of these three possible adverse effects (glycaemia and cortisol) are small in magnitude but when acting synergistically with a doubling of angiotensin II, they could still make a contribution.

Our study shows that aldosterone antagonism is extremely effective in lowering blood pressure as an add-on agent in type 2 diabetes patients with poorly controlled hypertension. But it also raises the possibility that any spironolactoneinduced benefits of blood pressure lowering on the endothelium might be offset by the worsening of glycaemic control, the increase in angiotensin II and possibly by an increase in cortisol, i.e. spironolactone may not reduce vascular events by the magnitude that its blood pressure-lowering alone would suggest. On the other hand, spironolactone might exert favourable anti-arrhythmic effects by way of its apparently beneficial effects on myocardial collagen and on QT interval length, as has also been seen in other populations [46, 47]. Further work is required to explore the full clinical consequences of the issues raised by this study.

Acknowledgements This research was funded by the Northwood Trust and Tenovus. We thank L. McFarlane and V. Godfrey for laboratory work, S. McLaren for logistical support and P. Donnan for statistical input.

Duality of interest A. D. Struthers has received honoraria from Pfizer, who are the makers of an aldosterone antagonist, and has also been an advisor to other companies making novel aldosteronemodulating drugs.

\section{References}

1. Booth GL, Kapral MK, Fung K, Tu JV (2006) Relation between age and cardiovascular disease in men and women with diabetes compared with non-diabetic people: a population-based retrospective cohort study. Lancet 368:29-36

2. Feskens EJ, Kromhout D (1992) Glucose tolerance and the risk of cardiovascular disease: the Zutphen Study. J Clin Epidemiol 45: $1327-1334$

3. Bryant W, Greenfield JR, Chisholm DJ, Campbell LV (2006) Diabetes guidelines: easier to preach than to practise? Med J Aust 185:305-309

4. Sivaprasad S, Jackson H (2007) Blood pressure control in type II diabetics with diabetic retinopathy. Eye 21:708-711

5. Pitt B, Zannad F, Remme WJ et al (1999) The effect of spironolactone on morbidity and mortality in patients with severe heart failure. Randomized Aldactone Evaluation Study Investigators. N Engl J Med 341:709-717

6. Pitt B, Remme W, Zannad F et al (2003) Eplerenone, a selective aldosterone blocker, in patients with left ventricular dysfunction after myocardial infarction. N Engl J Med 348:1309-1321

7. Joffe HV, Kwong RY, Gerhard-Herman MD, Rice C, Feldman K, Adler GK (2007) Beneficial effects of eplerenone versus hydrochlorothiazide on coronary circulatory function in patients with diabetes mellitus. J Clin Endocrinol Metab 92:2552-2558

8. Macdonald JE, Kennedy N, Struthers AD (2004) Effects of spironolactone on endothelial function, vascular angiotensin converting enzyme activity, and other prognostic markers in patients with mild heart failure already taking optimal treatment. Heart 90:765-770

9. MacFadyen RJ, Barr CS, Struthers AD (1997) Aldosterone blockade reduces vascular collagen turnover, improves heart rate variability and reduces early morning rise in heart rate in heart failure patients. Cardiovasc Res 35:30-34

10. Davies JI, Band M, Morris A, Struthers AD (2004) Spironolactone impairs endothelial function and heart rate variability in patients with type 2 diabetes. Diabetologia 47:1687-1694

11. Chapman N, Dobson J, Wilson S et al (2007) Effect of spironolactone on blood pressure in subjects with resistant hypertension. Hypertension 49:839-845

12. Calhoun DA (2007) Low-dose aldosterone blockade as a new treatment paradigm for controlling resistant hypertension. J Clin Hypertens (Greenwich) 9(Suppl 1):19-24

13. Bridges AB, Scott NA, McNeill GP, Pringle TH, Belch JJ (1992) Circadian variation of white blood cell aggregation and free 
radical indices in men with ischaemic heart disease. Eur Heart $\mathbf{J}$ 13:1632-1636

14. Guthikonda S, Sinkey C, Barenz T, Haynes WG (2003) Xanthine oxidase inhibition reverses endothelial dysfunction in heavy smokers. Circulation 107:416-421

15. Petrie JR, Perry C, Cleland SJ, Murray LS, Elliott HL, Connell JM (2000) Forearm plethysmography: does the right arm know what the left is doing? Clin Sci (Lond) 98:209-210

16. Wilkinson IB, Webb DJ (2001) Venous occlusion plethysmography in cardiovascular research: methodology and clinical applications. Br J Clin Pharmacol 52:631-646

17. Benjamin N, Calver A, Collier J, Robinson B, Vallance P, Webb D (1995) Measuring forearm blood flow and interpreting the responses to drugs and mediators. Hypertension 25:918-923

18. Petrie JR, Ueda S, Morris AD, Murray LS, Elliott HL, Connell JM (1998) How reproducible is bilateral forearm plethysmography? Br J Clin Pharmacol 45:131-139

19. Gokce N, Keaney JF Jr., Hunter LM et al (2003) Predictive value of noninvasively determined endothelial dysfunction for long-term cardiovascular events in patients with peripheral vascular disease. J Am Coll Cardiol 41:1769-1775

20. Modena MG, Bonetti L, Coppi F, Bursi F, Rossi R (2002) Prognostic role of reversible endothelial dysfunction in hypertensive postmenopausal women. J Am Coll Cardiol 40:505-510

21. Halcox JP, Schenke WH, Zalos G et al (2002) Prognostic value of coronary vascular endothelial dysfunction. Circulation 106:653658

22. Heitzer T, Schlinzig T, Krohn K, Meinertz T, Munzel T (2001) Endothelial dysfunction, oxidative stress, and risk of cardiovascular events in patients with coronary artery disease. Circulation 104:2673-2678

23. Schachinger V, Britten MB, Zeiher AM (2000) Prognostic impact of coronary vasodilator dysfunction on adverse long-term outcome of coronary heart disease. Circulation 101:1899-1906

24. Suwaidi JA, Hamasaki S, Higano ST, Nishimura RA, Holmes DR Jr, Lerman A (2000) Long-term follow-up of patients with mild coronary artery disease and endothelial dysfunction. Circulation 101:948-954

25. Vita JA, Keaney JF Jr (2002) Endothelial function: a barometer for cardiovascular risk? Circulation 106:640-642

26. Zannad F, Radauceanu A (2005) Effect of MR blockade on collagen formation and cardiovascular disease with a specific emphasis on heart failure. Heart Fail Rev 10:71-78

27. Davies J, Gavin A, Band M, Morris A, Struthers A (2005) Spironolactone reduces brachial pulse wave velocity and PIIINP levels in hypertensive diabetic patients. Br J Clin Pharmacol 59: $520-523$

28. Wong KY, Mac Walter RS, Douglas D, Fraser HW, Ogston SA, Struthers AD (2003) Long QTc predicts future cardiac death in stroke survivors. Heart 89:377-381

29. Salles GF, Deccache W, Cardoso CR (2005) Usefulness of QTinterval parameters for cardiovascular risk stratification in type 2 diabetic patients with arterial hypertension. J Hum Hypertens 19:241-249

30. He FJ, MacGregor GA (2001) Fortnightly review: Beneficial effects of potassium. BMJ 323:497-501

31. Schram MT, van Ittersum FJ, Spoelstra-de Man A et al (2005) Aggressive antihypertensive therapy based on hydrochlorothiazide, candesartan or lisinopril as initial choice in hypertensive type II diabetic individuals: effects on albumin excretion, endothelial function and inflammation in a double-blind, randomized clinical trial. J Hum Hypertens 19:429-437

32. Schiffrin EL (1996) Correction of remodeling and function of small arteries in human hypertension by cilazapril, an angiotensin I-converting enzyme inhibitor. J Cardiovasc Pharmacol 27(Suppl 2):S13-S18

33. Schiffrin EL, Park JB, Intengan HD, Touyz RM (2000) Correction of arterial structure and endothelial dysfunction in human essential hypertension by the angiotensin receptor antagonist losartan. Circulation 101:1653-1659

34. Schiffrin EL, Park JB, Pu Q (2002) Effect of crossing over hypertensive patients from a beta-blocker to an angiotensin receptor antagonist on resistance artery structure and on endothelial function. J Hypertens 20:71-78

35. Ghiadoni L, Magagna A, Versari D et al (2003) Different effect of antihypertensive drugs on conduit artery endothelial function. Hypertension 41:1281-1286

36. Matsumoto S, Takebayashi K, Aso Y (2006) The effect of spironolactone on circulating adipocytokines in patients with type 2 diabetes mellitus complicated by diabetic nephropathy. Metabolism 55:1645-1652

37. Guerci B, Bohme P, Kearney-Schwartz A, Zannad F, Drouin P (2001) Endothelial dysfunction and type 2 diabetes. Part 2: altered endothelial function and the effects of treatments in type 2 diabetes mellitus. Diabetes Metab 27:436-447

38. Kawano H, Motoyama T, Hirashima O et al (1999) Hyperglycemia rapidly suppresses flow-mediated endothelium-dependent vasodilation of brachial artery. J Am Coll Cardiol 34:146-154

39. Tesfamariam B, Brown ML, Cohen RA (1991) Elevated glucose impairs endothelium-dependent relaxation by activating protein kinase C. J Clin Invest 87:1643-1648

40. Touyz RM, Schiffrin EL (1999) Ang II-stimulated superoxide production is mediated via phospholipase D in human vascular smooth muscle cells. Hypertension 34:976-982

41. Touyz RM, Chen X, Tabet F et al (2002) Expression of a functionally active gp91phox-containing neutrophil-type $\mathrm{NAD}(\mathrm{P}) \mathrm{H}$ oxidase in smooth muscle cells from human resistance arteries: regulation by angiotensin II. Circ Res 90:1205-1213

42. Petrie MC, Padmanabhan N, McDonald JE, Hillier C, Connell JM, McMurray JJ (2001) Angiotensin converting enzyme (ACE) and non-ACE dependent angiotensin II generation in resistance arteries from patients with heart failure and coronary heart disease. J Am Coll Cardiol 37:1056-1061

43. Hollenberg NK, Fisher ND, Price DA (1998) Pathways for angiotensin II generation in intact human tissue: evidence from comparative pharmacological interruption of the renin system. Hypertension 32:387-392

44. Simmons WW, Ungureanu-Longrois D, Smith GK, Smith TW, Kelly RA (1996) Glucocorticoids regulate inducible nitric oxide synthase by inhibiting tetrahydrobiopterin synthesis and L-arginine transport. J Biol Chem 271:23928-23937

45. Yang S, Zhang L (2004) Glucocorticoids and vascular reactivity. Curr Vasc Pharmacol 2:1-12

46. Shah NC, Pringle SD, Donnan PT, Struthers AD (2007) Spironolactone has antiarrhythmic activity in ischaemic cardiac patients without cardiac failure. J Hypertens 25:2345-2351

47. Barr CS, Lang CC, Hanson J, Arnott M, Kennedy N, Struthers AD (1995) Effects of adding spironolactone to an angiotensin-converting enzyme inhibitor in chronic congestive heart failure secondary to coronary artery disease. Am J Cardiol 76:1259-1265 